\title{
Composite Pyrolysis of Biomass and Plastic for High-quality Fuel Oil over HZSM-5
}

\author{
Dongxue $\mathbf{Y u}^{1,2}$ \\ ${ }^{1}$ Sichuan Institute of Building Research, Chengdu, China \\ ${ }^{2}$ State Key Laboratory of Multiphase Complex Systems, Institute of Process Engineering, Chinese Academy of Sciences, Beijing, China
}

Email address:

dxyu163@163.com

\section{To cite this article:}

Dongxue Yu. Composite Pyrolysis of Biomass and Plastic for High-quality Fuel Oil over HZSM-5. American Journal of Chemical Engineering. Vol. 9, No. 2, 2021, pp. 39-46. doi: 10.11648/j.ajche.20210902.12

Received: April 15, 2021; Accepted: May 13, 2021; Published: May 24, 2021

\begin{abstract}
Catalytic co-pyrolysis of biomass and plastic is a promising technology to their resource recovery and energy conversion. For the traditional technologies, the two feedstocks are mechanically mixed (MM) to the co-conversion reaction. However, there are disadvantages in the MM mode process, such as mixing nonuniformity and inconvenient transportation of feedstocks, poor heat and mass transfer during pyrolysis and low yield of effective products. To solve the above issues, a composite pyrolysis of biomass and plastic for high-quality fuel oil was innovatively studied in this paper at a lab-scale fixed bed reactor using HZSM-5 as a catalyst. Through procedures including mechanical mixing, hot pressing and crushing granulation, a composite molding (CM) sample was prepared. Then the optimal conditions for fuel oil production of the CM sample were explored, and under which conditions products distribution were compared with pyrolysis from the common MM sample. And possible mechanism for high-quality fuel oil generation of the composite pyrolysis was put forward through characterization of sample properties. Results show that, under the optimal reaction conditions of the composite pyrolysis, the yield of fuel oil was increased by $34.8 \%$ and the yield of aromatics was increased by $50.7 \%$ compared with the conventional pyrolysis from MM sample. Advantages of the composite pyrolysis could be explained by the enhanced contact between biomass and plastic particles, which promoted a stronger synergy between the two derived intermediates and effectively improved mass and heat transfer during pyrolysis process.
\end{abstract}

Keywords: Biomass, Plastic, Co-pyrolysis, Composite Pyrolysis, Fuel Oil, Aromatics

\section{Introduction}

Biomass is an abundant and renewable energy with organic carbon, and plastic is a kind of derivatives from fossil fuels with unbiodegradable property [1]. Large amounts of waste biomass and plastics cause serious environmental pollution and waste of resources, but both have substantial energy contents [2]. Catalytic co-pyrolysis of biomass and plastic to produce fuel oils or chemical products is a promising technology to their resource recovery and energy conversion $[3,4]$.

During the catalytic co-pyrolysis process, plastic materials rich in carbon and hydrogen act as a hydrogen donor to biomass materials with hydrogen deficiency and oxygen enrichment characteristics [5,6]. Compared to the biomass individual pyrolysis, proportion of oxygenated compounds in liquid products can be reduced and polyreactions of unstable oxygenate intermediates toward char and coke can be limited, which improves both the quantity and quality of liquid fuel products significantly [7-8]. On the other hand, the agglomeration occurred in the pyrolysis of plastics alone can be alleviated by biomass particles during the co-pyrolysis process [9]. In addition, positive synergistic effects are observed compared to separate pyrolysis of the two feedstocks in terms of increased aromatics yield [10]. The oxygenated intermediates such as furans, aldehydes and phenols derived from biomass abstract hydrogen from alkanes and olefins derived from plastics, yielding the high value-added aromatics followed by dehydration through Diels-Alder reaction and hydrogen transfer as shown in Figure 1 [10-13]. 


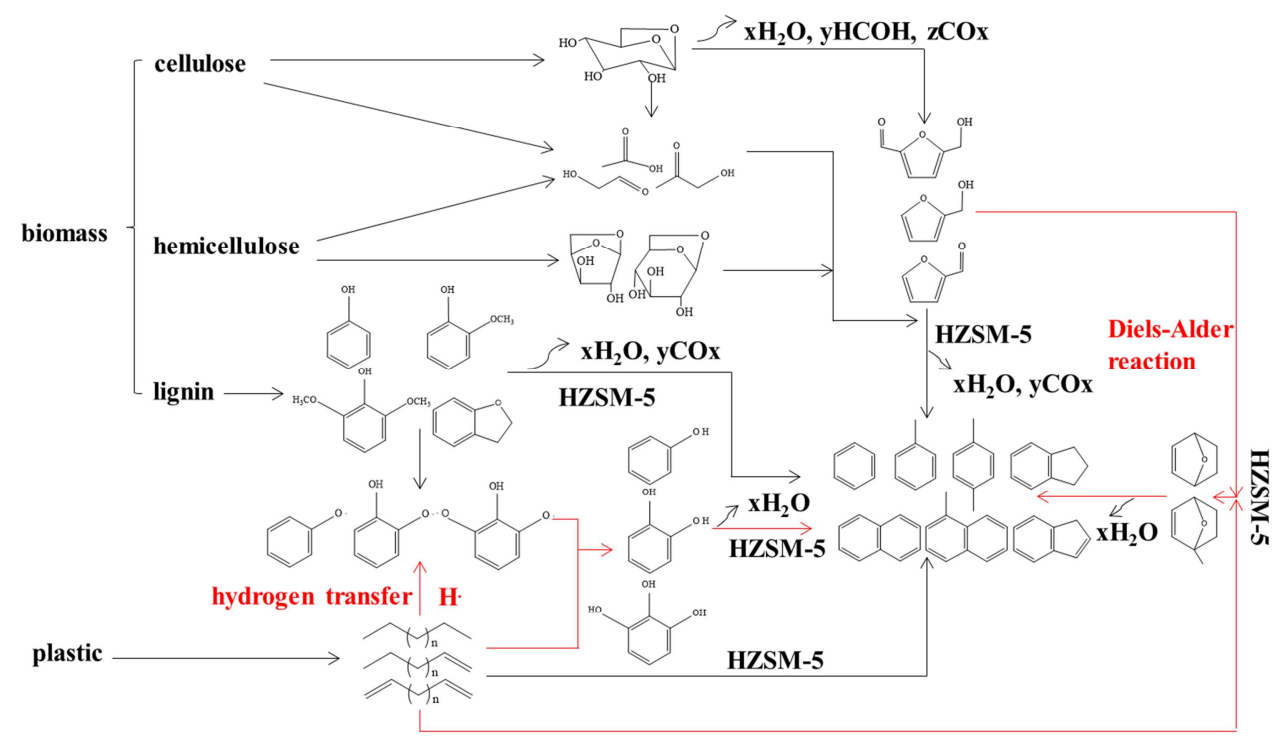

Figure 1. Diagram of synergistic reactions between biomass and plastic.

For the most technologies described in literatures, the biomass and plastic materials are mechanically mixed to the co-conversion reaction [5-8, 10-13]. However, there are significant differences between the two components in particle size, density, hardness, shape, heating state and so on. The traditional mechanical mixing (MM) process is difficult to mix the feedstocks evenly. Meanwhile, both biomass and plastics have low mass density and irregular shape, so the material transportation cannot be stability for large-scale continuous reaction. Furthermore, in the MM mode biomass and plastic materials are loose deposited together. The solid-solid contact mode of the two will affect the mass transfer and heat transfer during pyrolysis reaction, where the synergistic effect between volatile intermediates from the two may be weaken, thus limiting the occurrence of deoxygenation and aromatization reactions. In view of the above problems, this paper puts forward a novel composite molding $(\mathrm{CM})$ process on biomass and plastic to change the particles contact mode, through procedures of mechanical mixing, hot pressing and crushing granulation.

In the current study, catalytic pyrolysis of the prepared CM sample (composite pyrolysis) and the MM sample (conventional pyrolysis) from biomass and plastic were carried out on a fixed bed reactor over HZSM-5. Reaction conditions to achieve high-quality fuel oil were explored, including pyrolysis heating rate, reaction temperature and catalyst addition. Then, products distribution under the optimal conditions from composite pyrolysis and the conventional pyrolysis from MM sample were compared. Finally, a possible mechanism of producing high-quality fuel oil via the composite pyrolysis was deduced and analyzed, through comparation of chemical compositions, particle structures and pyrolysis behaviors between the two modes of feedstocks. This study provides a potential solution to tackle issues of waste biomass, plastics, or even wood-plastic composites (WPCs), on the industrial scale from the perspective of energy and environment.

\section{Materials and Methods}

\subsection{Materials}

Walnut shell (WNS, Henan Prov., China) and LDPE (Henan Jiekang Environmental Protection Technology Co., Ltd, China) were used as experiment compounds for biomass and plastic in this study. WNS was dried at $105^{\circ} \mathrm{C}$ for $2 \mathrm{~h}$ to remove moisture completely. The contents of hemicellulose, cellulose, lignin in WNS are $30.0 \mathrm{wt} \%, 34.1 \mathrm{wt} \%$, and 27.0 $\mathrm{wt} \%$, respectively. Proximate and ultimate analysis of WNS and LDPE samples are listed in Table 1.

Table 1. The proximate and ultimate analyses of WNS and LDPE.

\begin{tabular}{lllllllll}
\hline \multirow{2}{*}{ Sample } & \multicolumn{7}{l}{ Proximate analysis (wt\%, $\mathbf{d r y})$} & \multicolumn{2}{l}{ Ultimate analysis (wt\%, dry) } \\
\cline { 2 - 9 } & $\mathbf{V}$ & $\mathbf{A}$ & $\mathbf{F C}$ & $\mathbf{C}$ & $\mathbf{H}$ & $\mathbf{O}^{\mathbf{a}}$ & $\mathbf{N}$ & $\mathbf{S}$ \\
\hline WNS & 76.6 & 4.0 & 19.4 & 47.3 & 6.1 & 42.0 & 0.5 & 0.1 \\
LDPE & 99.8 & 0.2 & 0.0 & 85.8 & 14.0 & 0.0 & 0.0 & 0.0 \\
\hline
\end{tabular}

${ }^{\mathrm{a}}$ By difference.

HZSM-5 was employed as catalyst owing to its good shape selectivity [14, 15], which was firstly calcined at $550^{\circ} \mathrm{C}$ for $5 \mathrm{~h}$ and then was screened to less than $75 \mu \mathrm{m}$. The ratio of $\mathrm{SiO}_{2} / \mathrm{Al}_{2} \mathrm{O}_{3}$ is 30 , the specific surface area is $\geq 550$ $\mathrm{m}^{2} / \mathrm{g}$, and the pore volume is $\geq 0.17 \mathrm{~cm}^{3} / \mathrm{g}$.

\subsection{Composite Molding}

The dried WNS and LDPE samples were melting blended at $170 \pm 5^{\circ} \mathrm{C}$ with a definite mass ratio of $1: 1$ firstly, where the LDPE particles melted and forming a melt phase but the 
WNS particles were still in the solid form. Then the softening substance was hot-pressed under $2 \mathrm{MPa}$ maintained at $170 \pm$ $5^{\circ} \mathrm{C}$ to form blocks. After cooling the hard blocks were break into pellets with a diameter about $1 \mathrm{~mm}$ by an impact crusher, where at a smaller size LDPE could be separated with the compounds as thin films. Photo of the prepared CM sample is presented in Figure 2.

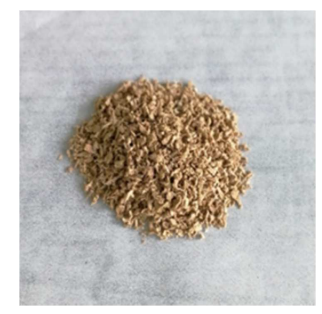

Figure 2. Photo of the prepared CM sample.

\subsection{TG-DTG Analysis}

Pyrolysis behaviors of feedstocks were characterized by a TG-DTG analysis during study on reaction mechanism. TG-DTG curves of WNS, LDPE, and their CM and MM samples were tested respectively using a thermogravimetric analyzer (Netzsch STA 449, Germany). Around $10 \mathrm{mg}$ sample was employed and heated from ambient temperature up to $700^{\circ} \mathrm{C}$ with a heating rate of $10^{\circ} \mathrm{C} / \mathrm{min}$ purged with nitrogen at $50 \mathrm{~mL} / \mathrm{min}$.

\subsection{Pyrolysis Operation}

Pyrolysis experiments were performed to compare the products distribution from $\mathrm{CM}$ and $\mathrm{MM}$ samples using a fixed-bed reactor, which schematic diagram is presented in Figure 3. The furnace was divided into three sections, whose temperatures could be individually controlled. The middle section was maintained at the target pyrolysis temperatures where the sample was positioned. The temperatures in the upper and lower sections were set to be a little lower than the middle one. Reactor in this device was a quartz tube with dimension of $\phi 46 \mathrm{~mm} \times 950 \mathrm{~mm}$. The reaction materials were put into a quartz basket with dimension of $\phi 30 \mathrm{~mm} \times 90$ $\mathrm{mm}$, which could be moved tracked by a stainless-steel wire $(\phi$ $0.3 \mathrm{~mm}$ ). Nitrogen with a flow rate of $150 \mathrm{~mL} / \mathrm{min}$ was used as carrier gas during reaction processes. Solid products including char derived from feedstocks and coke deposited on catalyst were left in quartz basket, while volatile products were condensed in an ethylene glycol-water cold-trap. Liquid products were collected in collecting-bottles, and gaseous products were collected in collecting-bags.

In each test, $10 \pm 0.01 \mathrm{~g}$ of feedstock samples were used. HZSM-5 was put on the top layer of the feedstock sample. The mass ratio of catalyst to feedstocks was set as $1: 8,1: 4,1: 2$ and 1:1 respectively to investigate the impact of its value. The samples were pyrolyzed at $450-850^{\circ} \mathrm{C}$ for purpose of obtaining the optimal temperature value. And two different heating rate conditions were operated. At slow heating pyrolysis condition, the samples were temperature-programmed heated with a rate of $10^{\circ} \mathrm{C} / \mathrm{min}$. At fast heating pyrolysis condition (just compared with the former), when the reactor was heated and stabilized at desired temperatures the quartz basket was rapidly pulled into the middle zone for pyrolysis. In all cases, the samples were hold at the target temperature for $10 \mathrm{~min}$. Three repeated tests were carried out to ensure accuracy and reliability of experimental results.

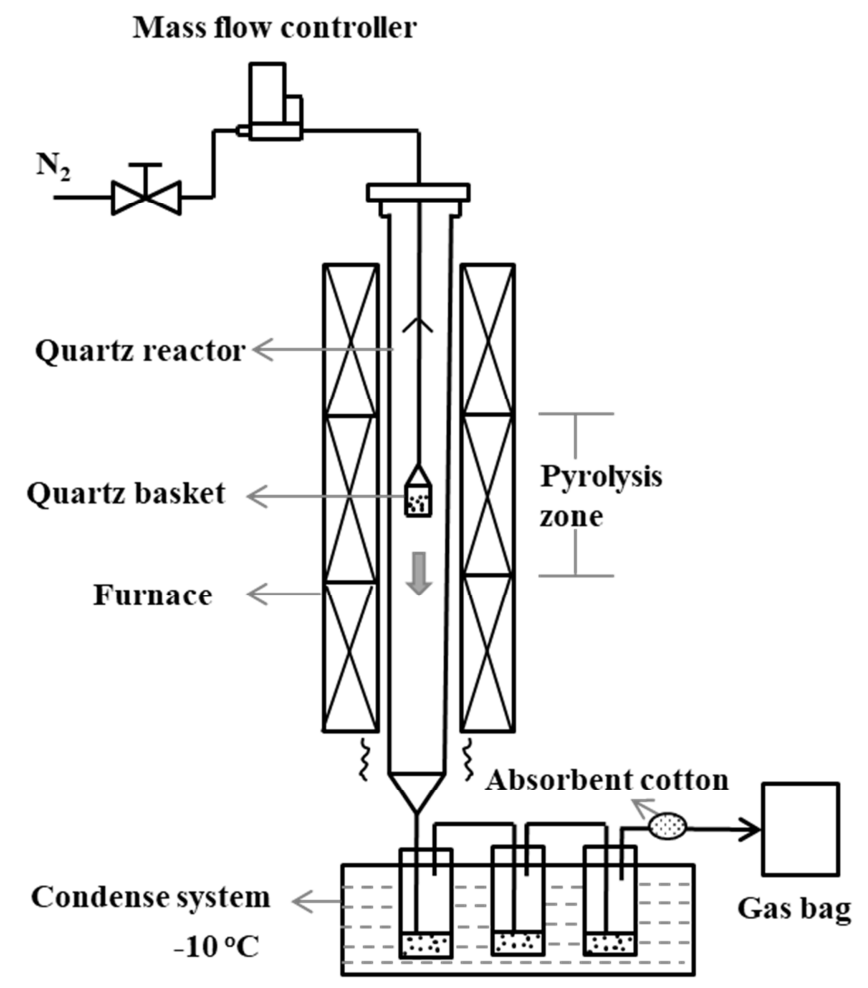

Figure 3. Schematic diagram of fixed-bed reactor.

\subsection{Products Analysis}

Gaseous products were analyzed by GC (Shimadzu GC-2014) and an external standard method was adopted to determine their yields. Liquid products were defined as the fuel oil in this study, and separated into aqueous phase and oil phase after centrifugation. The yields of each phase were determined by gravimetric method, respectively. Water amounts in aqueous fractions were tested by volumetric Karl Fischer Titrator (Mettler Toledo V20), then the yield of oil fraction in aqueous phase was calculated by deducting water. The yield of solid products was calculated according to the mass change of solid samples before and after reactions. Overall yield for every group of experiment was guaranteed to be over $95 \%$, indicating the experiment results closed well. The averaged results of three repeated tests were used in this paper.

Components in oil fraction of the aqueous phase and oil phase were detected by GC-MS (Shimadzu GC-2010 Plus) equipped with a polar column and another GC/MS (Varian CP-3800) equipped with a nonpolar column, respectively, which were compared with the standard mass spectra in NIST library. The relative peak area of a component in oil products is referred to as the selectivity to the component in this work 
[16], where it means that the component's peak area divided by the total peak area of all components excluding water. The yield of high-valued aromatics (Ya) is defined as follows according to reference [17]:

$$
Y \mathrm{a}=Y 1 \times S 1+Y 2 \times S 2
$$

Where, $Y 1$ and $S 1$ are corresponding to the yield and the aromatics selectivity of oil fraction from the aqueous phase, respectively. $Y 2$ and $S 2$ are corresponding to the yield and the aromatics selectivity of oil fraction from the oil phase, respectively.

\section{Results and Discussion}

\subsection{Optimization Experiment}

\subsubsection{Optimization of Heating Rate}

Since the pyrolysis heating rate has a direct influence on temperature gradient outside and inside the feedstock particles during heat transfer, and plays an important role on mass transfer during pyrolysis reactions. The products distribution would be different from slow heating pyrolysis and fast heating pyrolysis. The composite pyrolysis was investigated at two heating rates to obtain an optimal. As described in Section 2.4, in the case of slow pyrolysis, the feedstocks were temperature-programmed heated to $750^{\circ} \mathrm{C}$; in the case of fast heating pyrolysis, the feedstocks were suddenly placed at $750^{\circ} \mathrm{C}$ and rapidly heated to decompose; and the mass ratio of catalyst to feedstocks was all set as 1:4. The experimental data are presented in Table 2.

Table 2. Products distribution from composite pyrolysis at different heating rates.

\begin{tabular}{lll}
\hline $\begin{array}{l}\text { Products } \\
\text { distribution }\end{array}$ & Slow heating pyrolysis & Fast heating pyrolysis \\
\hline Products yield (wt\%) & & \\
Gas & 58.3 & 46.7 \\
Aqueous phase & 5.1 & 9.6 \\
Oil phase & 18.1 & 24.9 \\
Solid & 17.6 & 15.3 \\
Components selectivity in aqueous phase $(\%)$ & \\
Aromatics & 1.3 & 74.1 \\
Furans & 1.0 & 0.3 \\
AAAKs & \\
Phenols & 79.2 & 10.6 \\
Others & 18.5 & 4.4 \\
Components selectivity in oil phase $(\%)$ & 10.6 \\
Alkanes & 43.7 & \\
Olefins & 27.8 & 1.7 \\
Aromatics & 14.0 & 8.1 \\
Oxygenates & 14.5 & 82.0 \\
Aromatics yield (\%) & & 8.2 \\
& 2.6 & 22.6 \\
\hline
\end{tabular}

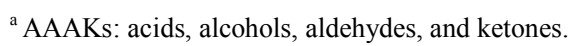

${ }^{\mathrm{b}}$ Others: mainly composed of alkanes and olefins.

Since the time interval of vapors released from WNS and LDPE was shorter via fast heating pyrolysis compared with the slow pyrolysis case, WNS and LDPE derived volatile compounds could more fully interact with each other. Further through positive synergistic effects generated between oxygenates produced from WNS (including furan, AAAKs (acids, alcohols, aldehydes, and ketones) and phenols) and hydrocarbons (including alkanes and olefins) produced from LDPE such as Diels-Alder reaction and hydrogen transfer, the oxygenate compounds and hydrocarbons were depleted and converted toward desired aromatics accompanying dehydration [18-20]. Meanwhile, the higher heating rate contributed to the conversion of gaseous and solid products toward the desired fuel oil (including aqueous and oil phase). Herein, considering the yield and quality of fuel oil, fast heating pyrolysis of the CM sample was adopted in the next to further optimize the pyrolysis products.

\subsubsection{Optimization of Reaction Temperature}

The mass ratio of catalyst to feedstocks was fixed at 1:4, and the effect of reaction temperature on products distribution was investigated. Results are shown in Figure 4. At high temperature the degradation of feedstocks was sharper, with the result that the yield of noncondensable gas increased but the yields of solid and aqueous phase decreased, and the yield of oil phase ascended then descended [21-23]. Moreover, high temperature contributed to the conversion of oxygenates and hydrocarbons toward aromatics, owing to the release of volatile vapors and the subsequent synergistic interactions between them in the presence of HZSM-5 [18-20]. The overall yield of aromatics increased firstly until reaching a maximum at $750^{\circ} \mathrm{C}$ and then decreased caused by the reduction of fuel oil's yield. Above all, the optimum reaction temperature to obtain the high value-added aromatic-rich oil for composite pyrolysis was $750^{\circ} \mathrm{C}$.
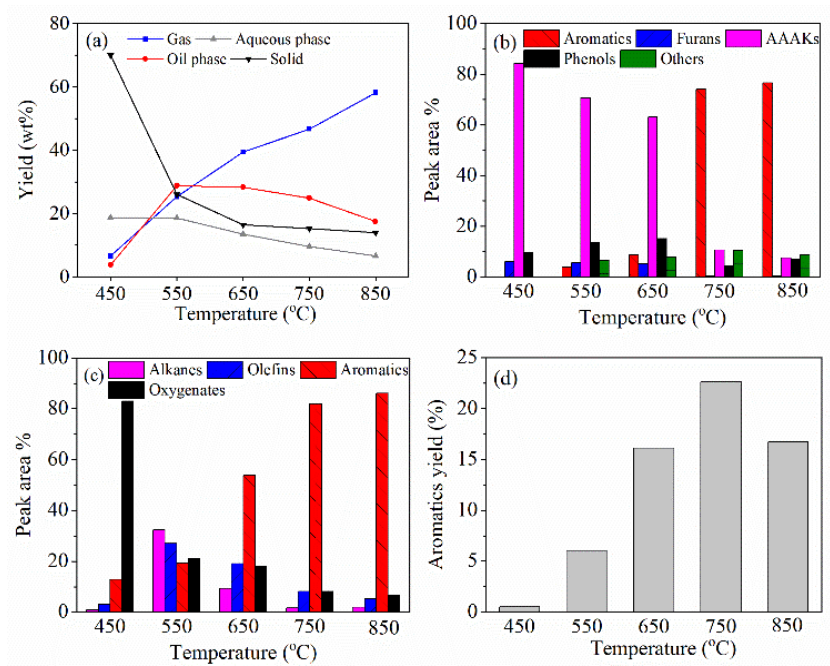

Figure 4. Products distribution from composite pyrolysis at different reaction temperatures: a) products yield; b) components selectivity in aqueous phase; c) components selectivity in oil phase; d) aromatics yield.

\subsubsection{Optimization of Catalyst Addition}

Fixed reaction temperature at $750^{\circ} \mathrm{C}$, the $\mathrm{CM}$ sample was pyrolyzed at different catalyst additions to investigate its influence. The products distribution is displayed in Figure 5. Since more catalyst amount could prolong resident time of the produced vapors inside catalyst pores [24], the cracking 
degree of WNS and LDPE molecules was subsequently strengthened. Thus, the yield of gaseous products increased, and the yield of oil phase products decreased. Whereas the yields of aqueous phase and solid products ascended at high catalyst proportion after descended, and the former might be caused by water produced by synergy between oxygenates and hydrocarbons, and the latter could be explained by char and coke produced by polycondensation reactions.
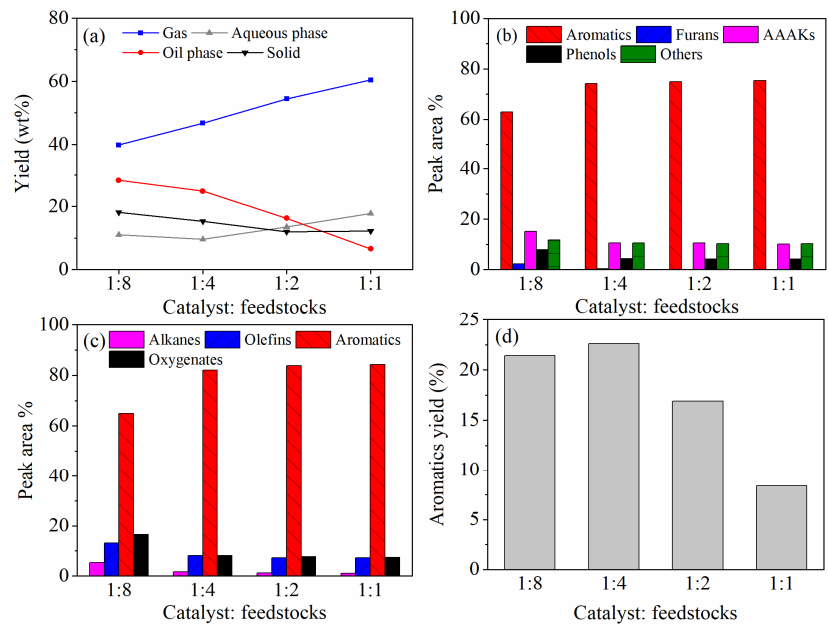

Figure 5. Products distribution from composite pyrolysis under different catalyst additions: a) products yield; b) components selectivity in aqueous phase; c) components selectivity in oil phase; d) aromatics yield.

For the case of studied, the aromatic products were always the main compounds both in aqueous phase and oil phase, and which selectivity rose gradually and became relatively stable when the mass ratio of HZSM-5: feedstocks was higher than 1:4. However, selectivities of oxygenates and aliphatic hydrocarbons dropped gradually with the catalyst addition. Those phenomena could be explained by the more active sites provided by high catalyst amounts, which promoted the synergy between oxygenates and aliphatic hydrocarbons and the conversion toward aromatics [18-20]. The aromatics yield ascended followed by descended as catalyst adoption, comprehensively considering its selectivity in aqueous phase and oil phase coupled with the fuel oil yield. The optimum mass ratio of catalyst to feedstocks was 1:4 to obtain the high value-added aromatic-rich oil for the composite pyrolysis.

Under the optimal reaction conditions of composite pyrolysis, the yield of fuel oil was $34.5 \mathrm{wt} \%$. The high value-added aromatics were dominant both in the aqueous phase and oil phase, in detail, the aromatics selectivity in the aqueous phase was $74.1 \%$, and that in the oil phase was $82.0 \%$, respectively. And the aromatics yield reached to $22.6 \%$.

\subsection{Products Comparation with the Conventional Approach}

\subsubsection{Slow Heating Pyrolysis}

Products distribution from the CM sample was compared versus the MM sample to study the effect of pyrolysis approach. Since the influence of heating rate on mass and heat transfer would be enlarged due to the differences in composition and thermal resistance characteristics between WNS and LDPE. Therefore, to obtain a comprehensive analysis for the composite pyrolysis and the conventional pyrolysis, experiments were performed both at low heating rate and high heating rate under the optimal reaction temperature and catalyst addition conditions.

The experimental data in the case of slow pyrolysis are presented in Table 3. It can be seen, similar results were gained from the pyrolysis of CM sample and MM sample in aspects of products yield and components selectivity, indicating that a similar reaction pathway might be experienced during the two modes of pyrolysis reaction.

Table 3. Products distribution from composite pyrolysis and conventional pyrolysis at slow heating rate.

\begin{tabular}{lll}
\hline $\begin{array}{l}\text { Products } \\
\text { distribution }\end{array}$ & Composite pyrolysis & Conventional pyrolysis \\
\hline Products yield (wt\%) & 58.3 & \\
Gas & 5.1 & 58.3 \\
Aqueous phase & 18.1 & 4.8 \\
Oil phase & 17.6 & 18.6 \\
Solid & 17.2 \\
Components selectivity in aqueous phase (\%) & \\
Aromatics & 1.3 & 1.2 \\
Furans & 1.0 & 1.1 \\
AAAKs & 79.2 & 79.3 \\
Phenols & 18.5 & 18.4 \\
Others & 0 & 0 \\
Components selectivity in oil phase (\%) & \\
Alkanes & 43.7 & 44.2 \\
Olefins & 27.8 & 27.2 \\
Aromatics & 14 & 13.6 \\
Oxygenates & 14.5 & 15.0 \\
Aromatics yield (\%) & & \\
& 2.6 & 2.6 \\
\hline
\end{tabular}

aAAKs: acids, alcohols, aldehydes, and ketones.

${ }^{\mathrm{b}}$ Others: mainly composed of alkanes and olefins.

Table 4. Products distribution from composite pyrolysis and conventional pyrolysis at high heating rate.

\begin{tabular}{lll}
\hline $\begin{array}{l}\text { Products } \\
\text { distribution }\end{array}$ & Composite pyrolysis & Conventional pyrolysis \\
\hline Products yield (wt\%) & 46.7 & \\
Gas & 9.6 & 55.4 \\
Aqueous phase & 24.9 & 6.2 \\
Oil phase & 15.3 & 19.4 \\
Solid & 74.1 & 15.4 \\
Components selectivity in aqueous phase (\%) & \\
Aromatics & 0.3 & 69.1 \\
Furans & 10.6 & 0.4 \\
AAAKs & & 13.6 \\
Phenols & 4.4 & 5.4 \\
Others & bomponents selectivity in oil phase (\%) & 11.5 \\
Comples & \\
Alkanes & 1.7 & 6.4 \\
Olefins & 8.1 & 14.3 \\
Aromatics & 82.0 & 68.8 \\
Oxygenates & 8.2 & 10.5 \\
Aromatics yield (\%) & & \\
& 22.6 & 15.0 \\
\hline
\end{tabular}

${ }^{\text {a }}$ AAAKs: acids, alcohols, aldehydes, and ketones.

${ }^{\mathrm{b}}$ Others: mainly composed of alkanes and olefins. 


\subsubsection{Fast Heating Pyrolysis}

However, as shown in Table 4, there are obvious differences in products distribution between the composite pyrolysis and the conventional pyrolysis from MM sample in the situation of a higher heating rate. In comparison, the yields of gaseous and solid products produced from the CM sample were much lower than that from the MM sample, but the yield of objective fuel oil has increased by $34.8 \%$ than the production from common MM sample. Meanwhile, in comparison, via the composite pyrolysis approach the selectivities of oxygenates, alkanes and olefins in their corresponding phases were significantly reduced, while the selectivity of aromatics was significantly improved. Consequently, the yield of high value-added aromatics was improved by $50.7 \%$ than the conventional pyrolysis method.

\subsection{Mechanism for High-quality Fuel Oil}

According to the above research, similar results were gained from composite pyrolysis and conventional pyrolysis under slow heating pyrolysis conditions in terms of pyrolysis behavior and products distribution. But, under fast heating conditions, the yield and quality of liquid products from composite pyrolysis were significantly improved than that from the MM sample, especially the yield of high value-added aromatics was much higher. It could be inferred that, the high-quality fuel oil from the CM sample was resulted from its unique material property from the other and the higher heating rate. To investigate the mechanism for high-quality fuel oil of the composite pyrolysis, characterization of the CM sample and the MM sample were performed in terms of chemical composition, particle structure and pyrolysis behavior.

\subsubsection{Analysis of Chemical Composition}

Proximate and ultimate analyses of the CM sample were tested and compared with the common MM sample. As listed in Table 5, the chemical composition of WNS and LDPE was not affected by the CM process.

Table 5. Proximate and ultimate analyses of CM sample and MM sample.

\begin{tabular}{|c|c|c|c|c|c|c|c|c|}
\hline \multirow{2}{*}{ Sample } & \multicolumn{3}{|c|}{ Proximate analysis (wt\%, dry) } & \multicolumn{5}{|c|}{ Ultimate analysis (wt\%, dry) } \\
\hline & $\mathbf{V}$ & $\mathbf{A}$ & FC & $\mathbf{C}$ & $\mathbf{H}$ & $\mathbf{O}^{\mathrm{a}}$ & $\mathbf{N}$ & $\mathbf{S}$ \\
\hline CM sample & 88.9 & 2.2 & 8.9 & 67.7 & 9.5 & 20.1 & 0.3 & 0.2 \\
\hline MM sample & 88.2 & 2.1 & 9.7 & 66.5 & 10.1 & 21.0 & 0.3 & 0.0 \\
\hline
\end{tabular}

${ }^{\mathrm{a}}$ By difference.

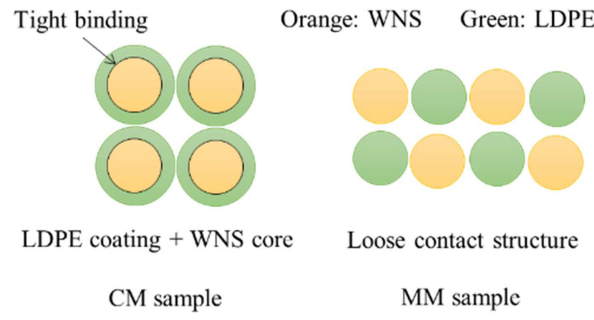

Figure 6. Particle structure of CM sample and MM sample.

\subsubsection{Analysis of Particle Structure}

Based on the CM operation procedure, as shown in Figure 6 particle structure of the CM sample must be changed from the MM sample. As for the MM sample, particles of WNS and LDPE contacted with each other in the form of loose accumulation. However, the melt blending treatment during CM sample preparation has made LDPE melt and form a mobile phase, which was coated on the surface of WNS solid particles, thus a particle structure of "LDPE coating + WNS

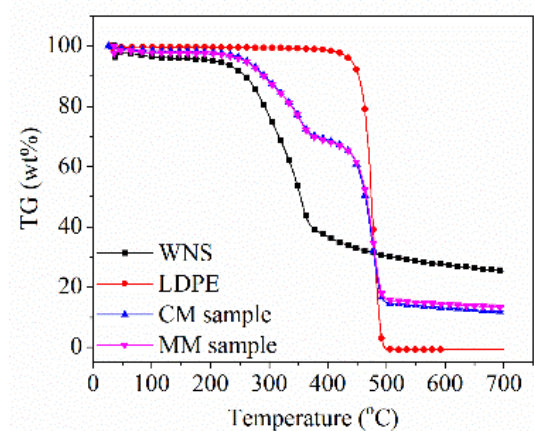

core" was formed after crushing and granulating. Meanwhile, through hot pressing occurred during the CM operation the LDPE coating and the WNS particles have been combined closely.

\subsubsection{Analysis of Pyrolysis Behavior}

Pyrolysis behaviors of the mixture and individual samples from WNS and LDPE were investigated through TG-DTG analysis. It can be seen from Figure 7, TG-DTG curves of the $\mathrm{CM}$ sample were nearly coincide with the MM sample, and both which were approximated to the simple superposition of separate pyrolysis results from WNS and LDPE. Results show that, there was no significant difference in pyrolysis behavior for the two modes of feedstocks under the temperature programmed pyrolysis condition, and in this case during the co-pyrolysis process the WNS was always decomposed firstly. This phenomenon can be used to explain why the two modes of feedstocks have similar products distribution at the slow heating pyrolysis condition (as shown in Table 3 ).

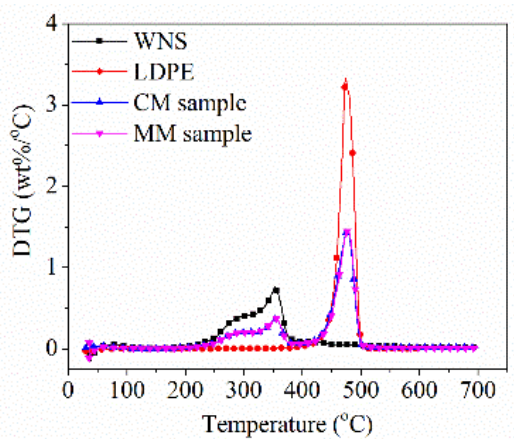

Figure 7. TG-DTG curves of WNS, LDPE, CM sample, and MM sample. 


\subsubsection{Explanation for High-quality Fuel Oil}

According to the above research, the producing of high-quality fuel oil from CM sample might be explained by its special particle structure and the higher heating rate.

During the slow heating process, there was relatively sufficient time for the mass transfer and heat transfer occurred in the following cases: from the furnace reactor to the feedstock particles, from the outside to inside of the feedstock particles, and between amounts of feedstock particles. It is quite possible that, in the early stage at low temperature during pyrolysis, a similar loose particle structure of "LDPE melt phase + WNS solid particles" has been formed for the CM sample and MM sample. Therefore, during the pyrolysis process the two types of feedstocks have lost their original material properties, further resulting in the similar pyrolysis behavior and products distribution as shown in Figure 7 and Table 3 , respectively.

However, during the fast heating pyrolysis reaction the feedstocks were suddenly put into a high-temperature environment, due to the poor thermal conductivity of WNS and LDPE [25], the CM sample and MM sample could maintain their original differences in particle structures as shown in Figure 6 . In view of the tight particle structure of "LDPE coating + WNS core" of CM sample, the existence of LDPE coating could effectively inhibit the preferential decomposition of cellulose and hemicellulose components with low thermal stability in WNS, thus the interaction of intermediate pyrolysis products from WNS and LDPE could be more fully. Herein, synergistic effects appeared between WNS derived oxygenates and LDPE derived hydrocarbons through Diels-Alder reaction and hydrogen transfer as shown in Figure 1, which could contribute to reaction of deoxygenation and the generation of high value-added aromatics. In addition, the mass and heat transfer during pyrolysis process could be promoted by the enhanced contact between WNS and LDPE particles in the MM sample. Thus, the quantity and quality of the objective fuel oil were all improved via the composite pyrolysis process.

\section{Conclusion}

A novel composite pyrolysis has been applied to the catalytic co-pyrolysis of biomass and plastic using walnut shell (WNS) and LDPE as model compounds over HZSM-5. The results from experiments at a lab-scale fixed bed reactor can be concluded as follows:

(1) A composite molding (CM) sample from WNS and LDPE was pre-prepared for the catalytic pyrolysis. When the composite pyrolysis was performed at $750^{\circ} \mathrm{C}$ with a catalyst ratio of 1:4, the high-quality fuel oil rich in aromatics was achieved, in which the aromatics selectivity in aqueous phase and oil phase were up to $74.1 \%$ and $82.0 \%$ respectively.

(2) Compared with conventional pyrolysis process from mechanical mixed (MM) sample, the composite pyrolysis had much less gas and solid production and lower selectivity to oxygenated compounds, whereas the fuel oil yield was increases by $34.8 \%$, and the yield of high value-added aromatics was increased by $50.7 \%$.

(3) Although the prepared CM sample and common MM sample have similar chemical composition, the contact mode of particles differed sharply. A tight particle structure of "plastic coating + biomass core" was formed before the composite pyrolysis. Consequently, the advantages of composite pyrolysis to produce fuel oil were attributed to the mixing uniformity of the biomass and plastic components, the advanced mass and heat transfer during pyrolysis process, and the enhanced synergistic effect between intermediate vapors from biomass and plastic.

\section{Acknowledgements}

This work was supported by the National Key R\&D Program of China (2018YFC1901302), National Natural Science Foundation of China (21808229), the "Strategic Priority Research Program" of the Chinese Academy of Sciences (XDA07010200).

\section{References}

[1] Uzoejinwa B, He X, Wang S, et al. Co-pyrolysis of biomass and waste plastics as a thermochemical conversion technology for high-grade biofuel production: Recent progress and future directions elsewhere worldwide. Energy Conversion and Management, 2018, 163: 468-492.

[2] Abnisa F, Mohd W, Wan A. A review on co-pyrolysis of biomass: An optional technique to obtain a high-grade pyrolysis oil. Energy Conversion and Management, 2014, 87: 71-85.

[3] Atutxa A, Aguado R, Gayubo AG, et al. Kinetic description of the catalytic pyrolysis of biomass in a conical spouted bed reactor. Energy and Fuels, 2005, 19 (3): 765-774.

[4] Sirous P, Oh D, Hong Y, et al. In-situ catalytic co-pyrolysis of yellow poplar and high-density polyethylene over mesoporous catalysts. Energy Conversion and Management, 2017, 151: 116-122.

[5] Yu D, Hui H, Li S. Two-step catalytic co-pyrolysis of walnut shell and LDPE for aromatic-rich oil. Energy Conversion and Management, 2019, 198: 1-8.

[6] Xu D, Xiong Y, Zhang S, et al. The synergistic mechanism between coke depositions and gas for $\mathrm{H}_{2}$ production from co-pyrolysis of biomass and plastic wastes via char supported catalyst. Waste Management, 2021, 121: 23-32.

[7] Brebu M, Ucar S, Vasile C, et al. Co-pyrolysis of pine cone with synthetic polymers. Fuel, 2010, 89: 1911-1918.

[8] Yang J, Rizkiana J, Widayatno WB, et al. Fast co-pyrolysis of low-density polyethylene and biomass residue for oil production. Energy Conversion and Management, 2016, 120: 422-429. 
[9] Shah SH, Khan ZM, Raja IA, et al. Low temperature conversion of plastic waste into light hydrocarbons. Journal of Hazardous Materials, 2010, 179 (1-3): 15-20.

[10] Alam M, Bhavanam A, Jana A, et al. Co-pyrolysis of bamboo sawdust and plastic: Synergistic effects and kinetics. Renewable Energy, 2020, 149: 1133-1145.

[11] Chattopadhyay J, Pathak TS, Srivastava R, et al. Catalytic co-pyrolysis of paper biomass and plastic mixtures (HDPE (high density polyethylene), PP (polypropylene) and PET (polyethylene terephthalate)) and product analysis. Energy, 2016, 103: 513-521.

[12] Oyedun AO, Gebreegziabher T, Ng DKS, et al. Mixed-waste pyrolysis of biomass and plastics waste- A modelling approach to reduce energy usage. Energy, 2014, 75: 127-135.

[13] Sajdak M, Muzyka R, Hrabak J, et al. Use of plastic waste as a fuel in the co-pyrolysis of biomass. Part I: The effect of the addition of plastic waste on the process and products. Journal of Analytical \& Applied Pyrolysis, 2015, 112: 298-305.

[14] Carlson TR, Jae J, Lin YC, et al. Catalytic fast pyrolysis of glucose with HZSM-5: The combined homogeneous and heterogeneous reactions. Journal of Catalysis, 2010, 270 (1): $110-124$.

[15] Kantarelis E, Yang W, Blasiak W. Effect of zeolite to binder ratio on product yields and composition during catalytic steam pyrolysis of biomass over transition metal modified HZSM5. Fuel, 2014, 122: 119-125.

[16] He L, Hui H, Li S, et al. Production of light aromatic hydrocarbons by catalytic cracking of coal pyrolysis vapors over natural iron ores. Fuel, 2018, 216: 227-232.

[17] Liu S, Xie Q, Zhang B, et al. Fast microwave-assisted catalytic co-pyrolysis of corn stover and scum for bio-oil production with $\mathrm{CaO}$ and HZSM-5 as the catalyst. Bioresource Technology, 2016, 204: 164-170.

[18] Liu S, Zhang S, Yu T, et al. Synergistic effect of co-pyrolysis of biomass and plastics. Chemisry and Industry of Forest Products, 2019, 39 (3): 34-42.

[19] Mullen CA, Dorado C, Boateng AA. Catalytic co-pyrolysis of switchgrass and polyethylene over HZSM-5: Catalyst deactivation and coke formation. Journal of Analytical \& Applied Pyrolysis, 2018, 129: 195-203.

[20] Xue Y, Bai X. Synergistic enhancement of product quality through fast co-pyrolysis of acid pretreated biomass and waste plastic. Energy Conversion and Management, 2018, 164: 629-638.

[21] Aysu T. Catalytic pyrolysis of Eremurus spectabilis for bio-oil production in a fixed-bed reactor: effects of pyrolysis parameters on product yields and character. Fuel Processing Technology, 2015, 129: 24-38.

[22] Sebestyén Z, Barta-Rajnai E, Bozi J, et al. Thermo-catalytic pyrolysis of biomass and plastic mixtures using HZSM-5. Applied Energy, 2017, 207: 114-122.

[23] Castaño P, Elordi G, Olazar M, et al. Insights into the coke deposited on HZSM-5, H $\beta$ and HY zeolites during the cracking of polyethylene. Applied Catalysis B, 2011, 104:91-100.

[24] Lee HW, Kim YM, Jae J, et al. Production of aromatic hydrocarbons via catalytic co-pyrolysis of torrefied cellulose and polypropylene. Energy Conversion and Management, 2016, 129: 81-88.

[25] Qi P, Chang G, Wang H, et al. Production of aromatic hydrocarbons by catalytic co-pyrolysis of microalgae and polypropylene using HZSM-5. Journal of Analytical and Applied Pyrolysis, 2018, 136: 178-185. 